\title{
Anything Relationship Management
}

\section{DOI 10.1007/s12599-012-0208-6}

\section{The Authors}

Dipl.-Kfm. Johannes Britsch

Institute for SME Research

University of Mannheim

L15, 1-6

68131 Mannheim

Germany

britsch@ifm.uni-mannheim.de

Dipl. Wirtsch.-Inf. Silvia Schacht ( $\varangle)$

Chair of Information Systems IV (ERIS)

University of Mannheim

L15, 1-6

68131 Mannheim

Germany

schacht@eris.uni-mannheim.de

Prof. Dr. Alexander Mädche

Chair of Information Systems IV (ERIS)

Institute for Enterprise Systems

University of Mannheim

L15, 1-6

68131 Mannheim

Germany

maedche@eris.uni-mannheim.de

Received: 2011-08-10

Accepted: 2012-01-07

Accepted after two revisions by

Prof. Dr. Sinz.

Published online: 2012-02-24

This article is also available in German in print and via http://www. wirtschaftsinformatik.de: Britsch J, Schacht S, Mädche A (2012) Anything Relationship Management. WIRTSCHAFTSINFORMATIK. doi: 10.1007/s11576-012-0315-5.

(c) Gabler Verlag 2012

\section{The Growing Importance of Networking}

Our lives are being influenced by an increasingly complex networking and relationship environment: over 800 million people now have Facebook accounts (Facebook Statistics 2011). We can now manage our domestic appliances remotely using mobile devices, for example, cookers, heating systems, and washing machines can be controlled from afar at the touch of a button. The so called Quick Response (QR) codes are being used more and more as a realtime medium for communicating product information. Web pages and applications exchange information about our preferences and our behaviors using programming interfaces.

There is a growing trend towards ever increasing network density, especially in the business environment. The digital linking of both people and things is becoming more and more popular. Existing business models are optimized by displaying relationships explicitly, thereby creating new business processes or, in some cases, entire business models. Relationship management was primarily used as a tool in the areas of marketing and sales within the greater context of Customer Relationship Management (CRM). Nowadays, applications are being used operationally in areas as wide ranging as logistics and human resources. A profitable side effect of this is the reinforced cross-organizational networking that takes place at a business network's level.

The concept of Anything Relationship Management (xRM) attempts to design and optimize the growing complexity of relationship structures. By using information and communication technologies (ICTs), xRM platforms provide a means for realizing various relationship-specific application scenarios.

\section{What is Anything Relationship Management?}

\subsection{History}

The systematic study of relationships has its origins in marketing. For a long time the subject was marked by a strong focus on individual transactions. According to McCarthy's concept of the "Four P's” (Product, Price, Place, Promotion), winning new customers has been a key success variable (McCarthy 1960).

In times of increasing market saturation, maintaining a sustainable relationship with existing customers becomes the focus of attention, and this process was termed Relationship Marketing (Berry 1983). Traditionally, however, relationship marketing was aimed at customers or at relationships between companies and their markets. This definition of Relationship Marketing has evolved into Relationship Management. According to Diller and Kusterer (1988) Relationship Management can be understood as being: "All the principles and guidelines plus any individual measures for the long term and targeted initiation, management and control of business relationships" - this remains a very theoretical description.

From an IT point of view, implementing these concepts has its roots firmly entrenched in marketing: it was at the end of the 1990s, when CRM began to take shape and specifically target sales markets and make use of ICT. CRM systems strive for the efficient and effective design of customer processes as well as a "single view on the pre-existing customer data of the company" (Hippner et al. 2006). The initial approaches to more generalized Relationship Management systems first appeared, albeit slightly delayed, in the guise of XRM (written with an upper case "X"): software manufacturers such as BroadVision named their strategic alignment of software solutions for the maintaining business relationships as Extended Relationship Management (Broadvision 1998). Although many IT analysts ran with the concept, and even published conceptualizations of XRM (Radjou et al. 2001), the market's focus remained, initially at least, firmly on CRM.

Around 2005, XRM finally gained attention: on the one hand as a generic term for specific applications such as Supplier Relationship Management (SRM) or Partner Relationship Management (PRM) and on the other hand under the heading of "integrating CRM". Schubert (2005) discussed the various levels of relationship management and their coordination using XRM. However, XRM's real "comeback" was in 2008, when it appeared as Anything Relationship Management and was written with a lower-case " $x$ ". Furthermore, Microsoft began to notice $\mathrm{xRM}$ and to position it as a new class of software for holistic 
Relationship Management. Today, xRM plays an important role in the strategic business orientation of CRM software companies such as CAS Software AG.

\subsection{Level of Development}

Analogous to Customer Relationship Management, Anything Relationship Management needs to be considered from a business and technology perspective.

From the business point of view, xRM (Diller and Kusterer 1988) is a strategic management approach that integrates and aligns all levels of relationships. In this sense, $x R M$ contributes to the systematic management of relationships to all partners, be they horizontal (e.g., joint ventures), vertical (e.g., franchising), or lateral co-operations (e.g., authorities). Relationship Management is essentially concerned with all manner of relationships and not just those involving customers, in essence any representatives of organizational stakeholders. Another key concept in the holistic xRM framework is that of involving both tangible and intangible relationships. Everything is included in the relationship structures from the material (e.g., fleet) to the intangible assets (e.g., contracts) and these are represented in the system in their entirety, which has a positive effect upon optimization.

The practical implementation of the concept is based on ICT. Usually xRM solutions are realized as platforms. This extensible foundation provides core functionalities that are used by multiple modules interacting with each other through interfaces (Tiwana et al. 2010). Thus, $\mathrm{xRM}$ platforms focus on the provision of high-value functions that improve relationship structures and also any related applications. At a conceptual level, the creation of business objects as well as their networking is supported. Business logic and associated user interfaces are based on the defined model. An essential part of this, which is due to the high service capacity of xRM platforms, is the pursuit of a generation approach, i.e. the largest possible part of the business logic and user interface is created automatically based on defined business objects. This approach also enables developers who do not have explicit technical training to produce xRM applications. Considering both perspectives, $\mathrm{xRM}$ can be defined as follows: $x R M$ describes a management concept in which all levels of relationships are coordinated and transparent, interactive processes are created. The implementation of the xRM concept is based on platforms and modular, domain-specific applications building upon these platforms.

xRM solutions should provide organizations with the ability to manage relationships of any type and between any of their entities with the objective of increasing stakeholder satisfaction: thus ensuring a valuable contribution to the long-term economic success of the organization. xRM platforms today are frequently offered in terms of cloud-based services, otherwise known as platformas-a-Service (PaaS) which provides an environment for xRM applications without having to resort to an IT infrastructure. Furthermore, xRM platforms allow the building of so-called platformbased ecosystems, consisting of software manufacturers, service companies, and users.

The effective distribution of xRM applications depends upon how effective the application markets for mobile applications are: just as with the apps markets for private users such as Apple's App Store.

\section{Practical Implementation}

In recent years, there have been a variety of different commercial xRM systems for sale on the market that are based on existing CRM solutions. Some good examples include: Microsoft Dynamics CRM 2011 with the xRM Application Framework, Salesforce.com with Force.com platform, Sugar CRM's "Sugar Platform Edition" as well as the CAS Open Platform on the German market. All of these solutions have already developed well established, platform-based ecosystems. For example, Salesforce.com built up the AppExchange marketplace which currently offers 1,331 xRM-built applications (Salesforce AppExchange 2011). The range of available applications provides solutions for all types of functional business areas, from human resources to finance. In addition, there is a range of industry specific solutions that address more specific requirements.

Generally, you can make a distinction between two application areas: internal organizational Relationship Management uses xRM platforms for documentation, analysis, and the influencing of relationships between entities within the organization. In contrast, organizationwide Relationship Management goes beyond the organizational boundaries supporting the initiation, the management, and the controlling of business relationships.

Human Resource Management is a typical area in which internal organizational Relationship Management is used to provide a means of systematically developing employees. Other examples include department specific applications that use modules and interfaces to optimize the impact of a situational application (Cherbakov et al. 2007). Your employees do not require any specific knowledge of development processes or associated technologies in such cases. And it is often the case that department specific applications, and the solutions they provide, are frequently found to be based on simple spreadsheets or database systems, whereas an xRM platform brings substantial additional benefits in the form of extra functionality. For example, any virtual teams using xRM can set up a digital project work space which is adapted to the needs and specific characteristics of the project and the team.

The following example of crossorganizational Relationship Management as applied to a German mechanical engineering company helps to illustrate these points. Within the framework of the needs analysis phase prior to the planned introduction of the CRM system, it was discovered that a customer dossier providing all employees with a comprehensive $360^{\circ}$ view of companywide processes brought useful holistic benefits that went beyond just the core processes of marketing, sales, and support. A CRM system displays key internal processes and also utilizes this information to further transparency by providing customers with an operational overview. In this case the customers wanted to have a means of being able to check current machine stocks or the locations of the machines. This was one of several key requirements that were implemented into the $\mathrm{xRM}$ platform. Based on the product master-data information contained in the ERP system, the xRM solution facilitated the mapping of various links between the products, structured customer data, and unstructured documents, and made them easily accessible to the various user groups. 
Also in the public sector, the management of complex inter-organizational relationships plays an increasingly important role. Several years ago now, the Karlsruhe Institute of Technology established a separate Relationship Management Office (KIT 2011). The creation of a strong network of students, staff, alumni, and representatives from industry, business, and science, as well as friends and supporters, is now an important aspect of the university's development. xRM platforms, especially with regard to flexibility, go far beyond existing campus management systems and provide technological support for establishing and maintaining such networks.

\section{Is This Important to Business and Information Systems Engineering?}

The new xRM paradigm provides a variety of relevant issues for Business and Information Systems Engineering (BISE), from both a business and technological point of view. Platform-based ecosystems are on the way to becoming the dominant approach to software development and the deployment of software-based services (Tiwana et al. 2010). Platforms are an interesting means of transferring the customized mass production models, from other industries, on to the software industry as way of satisfying "long tail needs". xRM platforms are especially good at highlighting new opportunities in the service industry for relationshipbased business applications. In combination with a market-based distribution model, such specific applications can easily be made available to users. Establishing a successful platform-based ecosystem requires a suitably designed platform and clearly defined governance mechanisms.

Another challenge facing the development of platform-based xRM applications is the application's granularity or smallest degree to which data can 'atomized' or reduced. There is already a number of competing xRM platforms on the market today.

This raises new questions on issues of platform interoperability, as well as the design of markets for cross-platform solutions with pre-configured $\mathrm{xRM}$ application packages which are based on one or more platforms. Cloud-based xRM platforms enable new networking scenarios on a company-wide or crossorganizational basis.

For example, in the area of procurement, the structured and unstructured interactions between customers and suppliers can be made more efficient through the use of transversal, platform-based applications (Koppenhagen et al. 2011). Moving beyond an "Internet of things" requires more than simply upgrading micro-electronic objects that communicate with one another. Linking objects to one another, or the Internet, requires clear relationship structures, and therefore, an xRM framework. At the heart of this approach is the expansion of Webbased services ("Internet of Services") to the "Internet of things". An xRM system links both real and virtual entities dynamically with respect to the context, and this is done using a variety of applications. Research in the field of BISE is currently focused upon identifying the design principles of suitable xRM applications.

Another interesting area of study is the interplay between standardized application software such as ERP and xRM platforms. Today, the interplay between ERP and CRM is well documented. However, $\mathrm{xRM}$ platforms still provide new opportunities for ERP functions that can be developed or expanded into the areas of tactical and strategic Human Resource Management. xRM platforms are characterized by flexibility and short development cycles, which makes them attractive as an approach for implementing busi- ness applications. Nevertheless, the development of independent xRM applications can lead to a highly heterogeneous application landscape. Therefore, new approaches will be needed to create an optimal balance between flexibility and standardization using xRM.

\section{References}

Berry LL (1983) Relationship marketing. In: Berry L, Shostack GL, Upah CD (eds) Emerging perspectives on service marketing. American Marketing Association, Chicago, pp 25-28

Broadvision (1998) BroadVision featured in BusinessWeek's 'InfoTech 10'. PR Newswire Association LLC, 1998-10-27

Cherbakov L, Bravery A, Goodman BD, Pandya A, Baggett J (2007) Changing the corporate IT development model: tapping the power of grassroots computing. IBM Systems Journal 46(4):1-20

Diller H, Kusterer M (1988) Beziehungsmanagement. Theoretische Grundlagen und explorative Befunde. Marketing ZFP 3:211220

Facebook Statistics (2011) http://www. facebook.com/press/info.php?statistics. Accessed 2011-11-13

Hippner H, Rentzmann R, Wilde KD (2006) Aufbau und Funktionalitäten von CRMSystemen. In: Hippner H, Rentzmann R, Wilde KD (eds) Grundlagen des CRM: Konzepte und Gestaltung, 2nd edn. Gabler, Wiesbaden, pp 43-74

KIT (2011) http://www.rsm.kit.edu. Accessed 2011-11-13

Koppenhagen N, Maedche A, Mueller B (2011) How do procurement networks become social? Design principles evaluation in a heterogeneous environment of structured and unstructured interactions. In: Proc ICIS, Shanghai

McCarthy EJ (1960) Basic marketing: a managerial approach. Irwin, Homewood

Radjou N, Orlov LM, Child M (2001) Apps for dynamic collaboration. The Forrester report, Cambridge, MA

Salesforce AppExchange (2011) http:// appexchange.salesforce.com/browse?type =Apps. Accessed 2011-11-13

Schubert V (2005) XRM: integrated customer relationship management for pharmaceutical innovation. PhD thesis, Technical University of Berlin

Tiwana A, Konsynski B, Bush AA (2010) Platform evolution: coevolution of platform architecture, governance, and environmental dynamics. Information Systems Research 21(4):675-687 